\title{
ASPECTOS PSICOLÓGICOS E PSIQUIÁTRICOS DO TRANSPLANTE DE MEDULA ÓSSEA
}

\author{
PSYCHOLOGICAL AND PSYCHIATRIC ASPECTS OF BONE MARROW TRANSPLANTATION
}

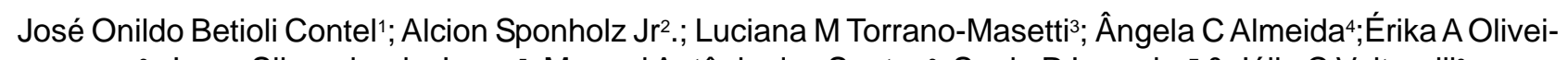
$\mathrm{ra}^{3}$; Jorge Silvandro de Jesus ${ }^{5}$; Manoel Antônio dos Santos ${ }^{6}$; Sonia R Loureiro ${ }^{7}$ \& Júlio C Voltarelli ${ }^{8}$

${ }^{1}$ Psiquiatra, docente do Depto. de Neurologia, Psiquiatria e Psicologia Médica da FMRPUSP, ${ }^{2}$ Psiquiatra, médico assistente do Depto. de Neurologia, Psiquiatria e Psicologia Médica da FMRP-USP, ${ }^{3}$ Psicóloga do Serviço de Psicologia Médica do HCFMRP e Mestranda da Faculdade de Filosofia, Ciências e Letras de Ribeirão Preto-U SP, ${ }^{4}$ Psicóloga do Serviço de Psicologia do HCFMRP e mestre pela FFCLRP-USP, ${ }^{5}$ Psiquiatra, ex-residente do Departamento de Neurologia, Psiquiatria e Psicologia Médica do HCFMRP, ${ }^{6}$ Psicólogo, docente do Depto. de Psicologia e Educação da Faculdade de Filosofia, Ciências e Letras de Ribeirão Preto-USP, ${ }^{7 P s i c o ́ l o g a, ~ d o c e n t e ~}$ do Departamento de Neurologia, Psiquiatria e Psicologia Clínica da FMRPUSP, ${ }^{8}$ Imunologista clínico, docente do Depto. de Clínica Médica da FMRPUSP

CorResPondÊncia: Prof. Dr. José Onildo Contel, Depto. de Neurologia, Psiquiatria e Psicologia Médica da FMRPUSP, Av. Nove de Julho, 980, 14025-000, Ribeirão Preto-SP

CONTEL JOB; SPONHOLZ JR A; TORRANO-MASETTI LM; ALMEIDAAC; OLIVEIRA EA; JESUS JS; SANTOS MA LOUREIRO SR \& VOLTARELLI JC. Aspectos psicológicos e psiquiátricos do transplante de medula óssea. Medicina, Ribeirão Preto,33: 294-311, jul./set. 2000.

RESUMO: A intensidade e a complexidade envolvidas no transplante de medula óssea (TMO), em seus vários níveis, produz profundos efeitos psicológicos no paciente, na família e na equipe profissional. Ignorar esta realidade e reduzir os problemas do TMO a seus aspectos puramente técnicos pode trazer consequências catastróficas para o paciente e seus familiares e ameaçar a sobrevivência da equipe. Neste trabalho, são discutidos três aspectos muito importantes de saúde mental no TMO, enfatizando a prática desenvolvida na Unidade de TMO do HCFMRP: 1) os múltiplos papéis desempenhados pela assistência psiquiátrica na Unidade de TMO, desde a prescrição de psicofármacos até o apoio à equipe multiprofissional em grupos de reflexão; 2) uma análise dos sentimentos vivenciados pelo paciente submetido ao TMO nas diferentes fases do transplante (pré, intra e pós-TMO) sob a perspectiva da esperança de cura; 3) uma avaliação da qualidade de vida dos pacientes submetidos ao TMO, a curto e médio prazos, integrando vários instrumentos de análise, incluindo técnicas projetivas.

UNITERMOS: Transplante de Medula Óssea. Psicologia. Psiquiatria. Estresse. Psicoterapia de Grupo. Qualidade de Vida.

\section{1- INTRODUÇÃO}

Os pacientes submetidos ao Transplante de Medula Óssea (TMO) vivenciam alguns problemas singulares ao enfrentar o transplante, decorrentes do próprio estresse a que são submetidos, desde o diagnóstico da doença, passando pelas várias fases do tratamento e suas complicações. São descritas na literatura várias alterações psicológicas e psiquiátricas nes- ses pacientes, tais como ansiedade, depressão, irritabilidade, desorientação, perda do controle, medo de morrer e perda da motivação. Eles começam a enfrentar a dor, o desfiguramento, a perda das funções sexuais, a dependência, o isolamento, a separação e a morte. Além disso, devem enfrentar a quimioterapia, a radioterapia, seus efeitos colaterais, idas freqüentes ao hospital, grandes despesas e o estresse acumulado que esses desafios trazem à família ${ }^{(1)}$. 
Além das vivências e angústias do paciente, considera-se o estresse que a equipe também enfrenta. Isto ocorre desde as primeiras reuniões com pacientes e familiares a respeito das informações sobre o procedimento do TMO, suas fases, suas possíveis complicações. Quando começam aparecer as primeiras manifestações colaterais da quimioterapia, assim como as complicações decorrentes de quadros infecciosos, é preciso que a equipe esteja bem estruturada, física e emocionalmente, tanto para dar ao paciente segurança, tranqüilidade e coragem para suportar cada fase, como para a própria equipe estar ciente das suas limitações. Brown \& Kelly, citados por Wolcott et al. em $1986^{(2)}$, descrevem oito estágios psicológicos do paciente submetido a TMO: 1) decisão de aceitar o transplante, 2) avaliação da internação e planejamento de cuidados, 3) regime de isolamento/condicionamento, 4) TMO propriamente dito, 5) pega da medula ou rejeição do enxerto, 6) possível desenvolvimento de GVHD, 7) preparação para alta, 8) adaptação fora do hospital. Em todos estes estágios, a atenção às necessidades emocionais do paciente é tão importante quanto os cuidados clínicos dirigidos aos problemas orgânicos, para assegurar o sucesso do procedimento.

A Consultoria Psiquiátrica ou Psiquiatria de Ligação vem sendo definida como a área da Psiquiatria Clínica que procura introduzir, em áreas não-psiquiátricas de hospitais gerais, um enfoque biopsicossocial na abordagem de doenças orgânicas. O termo Consultoria refere-se à função de fornecer opinião especializada a respeito do diagnóstico e manejo do paciente, considerando o seu comportamento e seu estado mental. O termo Ligação refere-se à função de unir grupos de profissionais com o propósito de colaboração efetiva e eficaz através de mediação. $\mathrm{O}$ consultor, portanto, funciona como um mediador entre o paciente e os membros da equipe e entre os profissionais de saúde mental e os outros profissionais envolvidos no cuidado do paciente. Em sua ação, procura ativar o diálogo e a cooperação interprofissional, de forma a evitar ou reduzir os sempre presentes conflitos entre os vários agentes em atividade no hospital geral, desde o paciente e seus familiares, até os membros da equipe prestadora de assistência.

O desenvolvimento de serviços de consultoria tem por base o reconhecimento de que a Psiquiatria aplicada no hospital geral melhora a qualidade do tratamento médico, agiliza a utilização do hospital e economiza o tempo do médico e dos demais membros da equipe multidisciplinar. Estes efeitos benéficos têm sido observados no Hospital das Clínicas da FMRPUSP (HCRP), onde, desde 1978, o Serviço de Interconsulta e Psiquiatria de Hospital Geral presta atendimento psiquiátrico: 1) ao paciente individual, pela consultoria tradicional, 2) a grupos homogêneos de pacientes com patologias clínicas especiais, pela interconsulta com grupos, 3) a grupos de apoio a profissionais que trabalham sob estresse intenso.

Na Unidade de TMO do HCRP, essas três modalidades de atendimento têm estado ativas desde a criação da Unidade, contando com a participação importante, além dos psiquiatras, de psicológos do Serviço de Psicologia Médica e dos outros membros da equipe multiprofissional, como será discutido neste Capítulo.

\section{2- PAPEL DO PSIQUIATRA NA EQUIPE DE TMO}

O psiquiatra desempenha múltiplos papéis ao se integrar a uma equipe de transplante de medula óssea: 1) funciona como triador de pacientes com alto risco emocional; 2) auxilia no acompanhamento destes pacientes; 3) orienta e fornece apoio aos familiares; 4) examina com os demais médicos da equipe as opções terapêuticas mais indicadas em função das interações medicamentosas com drogas psicotrópicas e possíveis efeitos psiquiátricos de drogas de ação sistêmica; 5) indica e realiza acompanhamento psicoterápico; 6) participa, juntamente com os outros membros da equipe, dos esforços necessários para redução do estresse relacionado ao trabalho neste tipo de unidade (Tabela I).

As avaliações pré-transplante consistem em colher história clínica da doença básica, investigando a presença de sintomas psíquicos que façam parte de um transtorno psiquiátrico e as repercussões pessoais e familiares posteriores à descoberta da doença. Além disso, levantam-se os impactos pessoais e familiares sobre a indicação para o TMO, com ênfase nas expectativas frente ao transplante (segurança/insegurança, tranqüilidade/desespero frente às etapas do transplante; medo de morrer, possibilidade de sucesso).

O psiquiatra deve considerar as preocupações do paciente, tais como sua saúde, a família, o relacionamento conjugal, preocupações financeiras, a atividade sexual e social e a auto-imagem em relação à doença propriamente dita. Na intervenção com os pacientes, o psiquiatra precisa também avaliar como o paciente enfrenta esses importantes problemas. Essas avaliações tornam-se a base para intervenções práticas para ajudar o paciente enfrentar sua doença ${ }^{(1)}$. 


\begin{tabular}{|c|c|c|}
\hline Papel desempenhado & Objeto de intervenção & Instrumento de intervenção \\
\hline Triagem pré-transplante & Pacientes candidatos ao TMO & $\begin{array}{l}\text { Anamnese psiquiátrica com ênfase na adaptação } \\
\text { prévia, diagnósticos psiquiátricos anteriores e risco } \\
\text { de suicídio }\end{array}$ \\
\hline $\begin{array}{l}\text { Acompanhamento } \\
\text { durante a internação }\end{array}$ & $\begin{array}{l}\text { Pacientes com alterações do } \\
\text { comportamento durante o TMO }\end{array}$ & $\begin{array}{l}\text { Diagnóstico diferencial entre condições } \\
\text { desencadeadas ou agravadas por alterações em } \\
\text { outros aparelhos e sistemas ou ação direta de } \\
\text { medicações e estados "funcionais". Uso de } \\
\text { psicoterapia e/ou psicofarmacoterapia }\end{array}$ \\
\hline Apoio aos familiares & $\begin{array}{l}\text { Familiares de pacientes do TMO, } \\
\text { com particular atenção ao doador }\end{array}$ & Psicoterapia \\
\hline Apoio à equipe & Equipe multiprofissional & $\begin{array}{l}\text { Discussão de casos difíceis, orientação em } \\
\text { situações especiais, participação em grupos de } \\
\text { reflexão }\end{array}$ \\
\hline
\end{tabular}

Wolcott et al. ${ }^{(2)}$ mostraram, já em 1986, que $15 \%$ a $25 \%$ dos pacientes submetidos ao TMO manifestam estresse emocional, baixa auto-estima, menor satisfação pessoal, menor atividade vocacional e menor relacionamento íntimo. $\mathrm{Na}$ experiência destes autores, durante o longo período de isolamento que se segue ao transplante, os pacientes apresentam ansiedade, sentimentos de depressão com crises de choro, sentem dificuldades em se concentrar, em estruturar e manter suas atividades diárias, mesmo as mais simples como leitura, piorando a sensação de isolamento e desenvolvendo sentimentos de tédio e irritabilidade. Durante esse período, tendem a se focalizar apenas em sua contagem de leucócitos e em sua alta antecipada, evitando conversar sobre sua doença ou suas chances de sobreviver. Durante o condicionamento e a fase precoce do TMO, o paciente vivencia um cenário bem estruturado, com visitas freqüentes da equipe e está preocupado principalmente com os efeitos colaterais da quimio/radioterapia, como mucosite, náuseas, vômitos, anorexia, fraqueza, sedação, alopécia, febre e dor. Neste período, em que espera os valores de contagem de leucócitos atingirem um número seguro e satisfatório, os pacientes costumam desenvolver problemas de comportamento ou ansiedade/depressão e sentimentos de perda de controle.

Mesmo após a estabilização das contagens de leucócitos e plaquetas, eles vivenciam ansiedade, decorrente da longa estadia hospitalar, tornando-se dependentes do hospital e dos amigos para satisfazer as suas necessidades físicas e emocionais. Frente a es- tas situações, o psiquiatra pode estimular o paciente a falar sobre seus medos, preocupações e perdas, estabelecer metas para o desenvolvimento de atividades e ocupação do tempo e sugerir que sejam trazidos alguns objetos de casa para aumentar o seu conforto.

Baker et al.em $1997^{(3)}$ relataram um estudo com uma grande amostra de pacientes adultos candidatos ao TMO e encontraram sintomas depressivos em um terço dos pacientes. Jacobsen et al., por sua vez, em $1998^{(4)}$ examinaram a prevalência e correlação de sintomas do Transtorno de Estresse Pós-Traumático (TEPT) entre 43 mulheres submetidas a TMO por câncer de mama. Observaram que $12 \%$ a $19 \%$ das pacientes apresentavam critérios para diagnóstico de TEPT e a intensidade da sintomalogia correlacionouse com maior tempo de internação, baixo nível educacional e doença avançada. Além dos sintomas de TEPT, as pacientes referiam uma saúde mental e física bastante comprometida e problemas de sono.

Klapheke em $1999^{(5)}$ destacou que alguns centros de transplante de órgãos sólidos consideram uma contra-indicação relativa ao transplante a presença de um transtorno afetivo ou de personalidade. Observou, ainda, que um diagnóstico de esquizofrenia, na fase ativa da doença, ou a presença de ideação suicida ou uma história de múltiplas tentativas de suicídio, levavam a uma contra-indicação absoluta ao transplante. Os pacientes portadores de um transtorno de ansiedade, ainda segundo esse autor, não possuem uma contra-indicação ao transplante, mas devem receber o tratamento adequado para controle dos sintomas 
antes do início do procedimento. Por analogia, esta orientação pode ser empregada no TMO, uma vez que não há estudos específicos sobre contra-indicações psiquiátricas ao TMO.

A presença de uma doença grave, com piora da qualidade de vida, associada a dor crônica e sentimentos de desesperança (vide secção 2) são fatores de risco para suicídio comumente presentes nos pacientes candidatos ao TMO. Outros fatores de risco que precisam ser avaliados são: a presença de um diagnóstico psiquiátrico, principalmente abuso de substâncias, transtornos afetivos (depressão e transtorno bipolar) e de personalidade, esquizofrenia, solidão (ser solteiro ou viúvo), estar desempregado ou com a situação financeira comprometida e apresentar uma história de tentativas de suicídio prévias. Pacientes que apresentam estas condições devem ser investigados de forma aberta e compreensiva sobre a ocorrência de ideação suicida atual ${ }^{(6,7)}$ antes de serem transplantados.

Um paciente que esteja sendo submetido ao TMO e que desenvolva um distúrbio psiquiátrico deve ser identificado precocemente e iniciado acompanhamento psicoterápico e psicofarmacológico, como será descrito a seguir.

\subsection{Abordagem psicoterapêutica no TMO}

Com relação ao acompanhamento psicoterápico, vale lembrar que a clarificação, explicação e reasseguramento, embora fazendo parte das técnicas psicoterápicas, não são exclusivas desta prática e devem ser ativamente estimuladas em toda a equipe, pois apresentam grande poder de tranqüilização sobre o paciente.

Goves \& Kucharski ${ }^{(8)}$ referem-se à psicoterapia como sendo tanto um procedimento tanto contínuo e processual, quanto uma interação de poucos minutos, na qual apenas umas poucas frases são trocadas, desde que elas exerçam sua função terapêutica. $\mathrm{O}$ psiquiatra consultor na unidade de transplante deve saber ouvir e responder em três níveis: médico, social e psicológico, simultaneamente. O sucesso dessa intervenção depende da habilidade em compreender, rapidamente, como a personalidade do paciente está interagindo com o adoecimento e com os procedimentos terapêuticos propostos. Os autores apontam que esse trabalho se inicia com a compreensão do por que a intervenção psicoterápica está indicada e dividem essas indicações em três grandes categorias: 1) problemas com a cognição (delírio, psicose, negação excessiva); 2) problemas com o afeto (ansiedade, depressão, apatia, hostilidade) e 3) problemas de comportamento (dependência, falta de colaboração, comportamento manipulativo ou hostil).

A psicoterapia indicada para problemas com a cognição consiste no reconhecimento da natureza do prejuízo à cognição e, tanto quanto possível, na ajuda ao paciente para recuperar este déficit. Alterações da consciência, da percepção e da capacidade em manter a atenção, além de falhas na memória, podem estar relacionadas a uma série de eventos presentes durante a internação para o TMO, desde o isolamento durante um longo período de tempo, a rotina das atividades e horários, até o efeito tóxico de determinadas medicações como fenitoína, ciclosporina ou aciclovir, por exemplo ${ }^{(9,10)}$. O uso de objetos para orientação, como relógio e calendário, o contato com familiares e o cuidado com a orientação clara e objetiva antes de qualquer procedimento, são intervenções terapêuticas num sentido amplo e eficaz nessas situações. Em um sentido mais estrito, o emprego da negação como o predominante mecanismo de defesa do paciente deve ser avaliado cuidadosamente pelo psiquiatra consultor, que poderá intervir, usando o esclarecimento e o apoio como facilitadores para modificação do comportamento e aceitação da realidade.

Goves \& Kucharski ${ }^{(8)}$ apontam que os afetos tornam-se um problema ao longo da internação de um paciente quando eles são inapropriados, demasiadamente intensos ou autônomos, ou seja, estão além da capacidade do indivíduo ou do meio em modificálos. Assim, a base de uma psicoterapia voltada para distúrbios do afeto está no reconhecimento das causas deste distúrbio e na adequação desses sentimentos com relação à intensidade e expressão. Para tanto, é fundamental que, uma vez descartada a possibilidade das alterações afetivas estarem relacionadas a uma condição médica geral ou ao efeito tóxico de alguma medicação, o psiquiatra consultor realize uma investigação psicodinâmica para formulação de uma hipótese compreensiva e estabeleça uma intervenção psicoterápica. Essa formulação se dá a partir do conhecimento da história de vida do paciente e das correlações afetivas que o paciente realiza a partir do seu adoecimento e da forma como encara o tratamento. $\mathrm{O}$ trabalho psicoterápico consistirá em reconhecer essas correlações de forma a devolver ao paciente sua condição de compreender e expressar de forma mais clara e apropriada suas emoções. Muitos pacientes apresentam dificuldades em aceitar ou compreender seus sentimentos de raiva, tristeza e frustração e reagem negativamente às tentativas de abordagem afetiva e, 
neste contexto, a psicoterapia pode contribuir para aproximar os pacientes de suas necessidades de expressão afetiva.

De forma semelhante, pacientes com alterações do comportamento necessitam de que o psiquiatra consultor compreenda as relações entre seu comportamento mal adaptado, os afetos presentes e o seu entendimento (cognição) acerca do seu estado, da doença e do tratamento proposto. Muitas vezes, um comportamento agressivo resulta de sentimentos de raiva ou frustração que são alimentados por idéias de desesperança acerca da sua possibilidade de recuperação ou adaptação.

Outra alteração de comportamento freqüentemente observada é a dependência patológica, que apresenta as seguintes manifestações: uma intensa e constante necessidade de atenção e reasseguramento, solicitações freqüentes de medicações ansiolíticas e analgésicas, solicitações manipulativas e ambivalentes de demonstração afetiva e comportamento caótico, desorganizado, destrutivo ou passivo-agressivo. De uma forma menos intensa, estas manifestações são relativamente comuns, mesmo em pacientes emocionalmente saudáveis, que são submetidos a longos períodos de internação. A dependência patológica na sua forma mais intensa é própria de pacientes com transtornos de personalidade. Eles habitualmente apresentam sentimentos de vazio interior e baixa auto-estima, mesmo na ausência de doença física, apresentam um grande desejo de proximidade, ao mesmo tempo em que temem o desenvolvimento de intimidade. A abordagem psicoterápica desses pacientes exige uma comunicação clara entre os membros da equipe e o paciente, de modo a não desafiar sua postura defensiva e, por vezes, arrogante e um acompanhamento contínuo pela equipe, procurando um distanciamento ótimo: nem muito perto, desafiando a necessidade de privacidade, nem muito longe, alimentando as fantasias de abandono. Além disso, quando necessário, devese recorrer ao uso de medicações tranqüilizantes para diminuir as "explosões" emocionais do paciente e ser firme na colocação de limites quanto a comportamento auto ou heteroagressivo, usando da contenção física e sedação se necessário ${ }^{(8)}$.

\subsection{Abordagem psicofarmacológica no TMO}

Quanto ao uso de psicofármacos, observamos que grande parte dos pacientes submetidos ao TMO apresenta, em algum momento do transplante, sinais de ansiedade intensa, que podem ser controlados com o uso de ansiolíticos benzodiazepínicos. Em nossa expe- riência, temos preferido o uso de lorazepam $2 \mathrm{mg}$ administrados preferencialmente nos períodos identificados como de maior ansiedade. De fato, Cassem \& Hackett ${ }^{(11)}$ salientam a importância do uso do lorazepam neste tipo de situação por apresentar meia vida curta, não ter subproduto ativo mielotóxico e nem metabolização hepática. O manejo de sintomas depressivos deve ser feito levando-se em conta a situação do transplante, a programação terapêutica para o paciente e sua responsividade afetiva à terapia. Um paciente com humor não responsivo ao acompanhamento psicoterápico, persistentemente deprimido por mais de duas semanas, com situação clínica estável, pode se beneficiar do uso de antidepressivos. Os inibidores de recaptação da serotonina, como a fluoxetina e a sertralina, podem ser a medicação preferencial nestes casos, pelo baixo perfil de efeitos colaterais, fácil administração, e efeito sobre a ansiedade. $O$ cuidado maior relacionado a esses agentes está na inibição das enzimas do complexo de metabolização farmacológica do citocromo $\mathrm{P} 450$, o que pode levar a uma interação medicamentosa prejudicial com outras drogas que o paciente esteja em uso A ciclosporina, por exemplo, tem seu nível sérico aumentado quando interage com a fluoxetina, o mesmo não acontecendo com a sertralina. Assim, a administração de antidepressivos deve ser cuidadosamente estudada pelo conjunto da equipe mé$\operatorname{dica}^{(12)}$.

Outra classe de psicofármacos que, por vezes, é usada nos pacientes do TMO são os neurolépticos. Habitualmente, são indicados em duas situações: no controle de sintomas psicóticos e comportamentais resultantes dos estados confusionais agudos ou do estado de delirium. Os estados confusionais agudos são caracterizados por: capacidade reduzida para manter a atenção, pensamento desorganizado, nível reduzido da consciência, perturbações perceptivas, perturbação do ciclo sono-vigília, psicomotricidade aumentada ou diminuída, desorientação e prejuízo da memória. Estes sintomas se instalam em curto período de tempo e flutuam ao longo do dia, geralmente com piora à noite. $\mathrm{O}$ surgimento destes estados confusionais pode estar relacionado a desordens sistêmicas, neurológicas, tóxicas, farmacológicas, metabólicas ou a causas múltiplas e seu tratamento está centrado na identificação da causa básica e correção da mesma. Quando isto não for possível e o paciente apresentar intensa alteração do comportamento, com agitação psicomotora, o haloperidol pode ser usado para controle da manifestação comportamental, em doses tituladas a partir de 0,5 a $1 \mathrm{mg}$ a cada 30 minutos $^{(13)}$. 


\subsection{Grupos de apoio para a equipe de TMO}

Nos grupos de apoio a profissionais da saúde, segundo Vinogradov \& Yalom $^{(14)}$, queixas de estar assoberbado pelo trabalho a ponto de ficar "à beira de um ataque de nervos" são comuns e podem incluir as seguintes causas: 1) frustração e irritabilidade devidas à carga de trabalho excessiva, número insuficiente de profissionais e apoio administrativo precário; 2) inconformidade, ou mesmo raiva, pela inadequada distribuição, real ou imaginária, do poder na equipe; 3) sentimentos de insegurança e inadequação derivados de enormes responsabilidades profissionais; 4) desconforto provocado pela pressão constante para o desempenho profissional sob estresse e 5) atritos pessoais entre profissionais da mesma ou de diferentes especialidades.

Nas Unidades de TMO, principalmente naquelas em que predominam os transplantes alogênicos, estes fatores são agravados pela significativa mortalidade pós-transplante de pacientes que, muitas vezes, são admitidos em condições aparentes de perfeita saúde física e mental, como os portadores de leucemia mielóide crônica em fase crônica e de leucemias agudas em remissão completa. De fato, o envolvimento técnico em procedimentos médicos de alto risco e que podem resultar na morte de $50 \%$ ou mais dos pacientes, dependendo das suas condições, tem o poder de gerar um estresse contínuo nos profissionais em todos os níveis, não raro percebido como incontornável e definitivo.

A Unidade de TMO do HCFMRP foi instalada em 1992 e, no seu início, teve suas atividades interrompidas três vezes, tanto pela falta de pessoal técnico treinado, principalmente de enfermagem, para suprir as desistências, como pela persistência, na equipe remanescente, de níveis de estresse percebidos como insuportáveis. Ocorreu como que um colapso mental da equipe, que inviabilizou o trabalho multidisciplinar. Em resposta a esta situação, instalou-se em novembro de 1994 um grupo de apoio aos profissionais da equipe de TMO, com o objetivo inicial de reduzir o estresse oriundo, principalmente, da elevada taxa de mortalidade entre os pacientes tratados pela equipe.

O grupo de apoio psicológico à equipe de TMO do HCFMRP funciona há cerca de 6 anos com as seguintes características: 1) encontro semanal de uma hora de duração, às 6as. feiras, das 12:30 às 13:30 h; 2) coordenação de psicoterapeuta de grupo experimentado $^{(15)} 3$ ) aberto a todos os profissionais da equipe, que são encorajados em participar, mas sem obri- gatoriedade; 4) ambiente facilitador da livre discussão circulante entre os técnicos presentes, sem barreiras hierárquicas entre eles; 5) temática restrita a assuntos internos que mobilizaram a Unidade durante a semana, enfocando o relacionamento interpessoal, segundo percebido no grupo ou no ambiente de trabalho; 6) presença constante e ativa das chefias médica e de enfermagem e da equipe médica, mas apenas ocasional dos profissionais paramédicos, incluindo a enfermagem. O líder do grupo encoraja os membros a dividir seus pontos de vista e focar sua atenção nos problemas do dia-a-dia da Unidade, trata os componentes do grupo como seus colegas e não como seus pacientes. Assim, as interpretações transferenciais são evitadas e, quando praticadas, são explicadas de onde derivam e apresentadas como colaboração do psicoterapeuta para ajudar o grupo a entender melhor seus conflitos.

Desde a sua criação, a Unidade de TMO do HCFMRP tem sofrido persistentemente situações comuns a outros serviços públicos de saúde do país: recursos limitados para manutenção e expansão, congelamento de salários do pessoal técnico e redução drástica do seu número, decorrente de dificuldades de contratação e mudanças nas condições hoteleiras, comprometendo o conforto e segurança da equipe e dos pacientes. Estes fatores, na maioria das vezes fora do alcance da intervenção da equipe, potencializam dramaticamente o estresse vivido por ela no cuidado aos pacientes transplantados.

O trabalho na Unidade de TMO gera elevado grau de estresse na equipe multidisciplinar. $\mathrm{O}$ alto índice de mortalidade entre os pacientes, cuja repetição, ao longo do tempo, tem o poder de causar um efeito estressante cumulativo, exige atenção e elaboração. O sofrimento físico dos pacientes, instalado agudamente e inflingido a eles pelo depauperamento físico e pelas complicações do TMO, que provocam dor e desconforto físico e emocional, têm um enorme poder de contagiar, tanto a equipe, como familiares e acompanhantes, trazendo consequências arrasadoras para a coesão da equipe. Neste contexto, são comuns conflitos interpessoais intensos e exasperantes, percebidos como sugadores da energia da equipe e vistos como insuperáveis entre seus membros. A equipe de TMO costuma responder a esta situação com momentos de fragmentação interna, de grau variável, que compromete o cuidado do paciente e ameaça a estabilidade da equipe. $\mathrm{O}$ exame destes conflitos, por si só, justifica a existência do grupo de apoio psicológico aos profissionais da Unidade de TMO. 
Nos seus seis anos de funcionamento, a psicoterapia de grupo de apoio à equipe de TMO do HCFMRP tem desempenhado as seguintes funções: 1) servir de assessoria permanente para o exame da relação médico/técnico-paciente; 2) educar os membros da equipe multidisciplinar em relação aos aspectos psicodinâmicos e psicossociais do transplante, aos modelos úteis e às estratégias particulares de manejo de cada paciente e de enfrentamento de estresse intraequipe; 3) ajudar a equipe a se adaptar ao estresse do dia-a-dia no trabalho; 4) melhorar o desempenho individual no ambiente de trabalho; 5) aprimorar a moral e a coesão da equipe multidisciplinar e diminuir a exclusão, o abandono e a rotatividade dos membros da equipe; 6) patrocinar um melhor tratamento médico aos pacientes. Esta experiência foi relatada em eventos científicos nacionais e internacionais de $\mathrm{TMO}^{(16)}$ e na literatura psiquiátrica especializada ${ }^{(17)}$.

Não seria exagerado afirmar que o funcionamento contínuo do grupo de apoio à equipe da Unidade de TMO do HCFMRP, desde as suas primeiras crises, tem contribuído, não só para aperfeiçoar suas atividades e seu ambiente de trabalho, mas, sobretudo, para permitir sua sobrevivência. Adaptado às condições locais de cada Unidade, este modelo poderá desempenhar o mesmo papel em outros centros do país, a maioria dos quais enfrenta situações muito semelhantes às apresentadas nesta secção.

\subsection{Conclusão: Acompanhamento psiquiátrico no TMO}

Encontramos na literatura uma diversidade de experiências em relação ao acompanhamento psiquiátrico na unidade de TMO. Apesar da heterogeneidade de abordagens, este acompanhamento é recomendado, quase unanimemente, para ser realizado desde o início do procedimento, não somente com o paciente, mas também com os familiares e com a equipe. Intervenções psicoterápicas individuais ou grupais auxiliam muito nesse processo, sendo que as técnicas cognitivocomportamentais e de relaxamento mostraram ser efetivas para o alívio do sofrimento e angústia experimentados pelo paciente. Nesta secção, discutiu-se a importância da presença do psiquiatra dentro da unidade de TMO, suas contribuições potenciais e as estratégias terapêuticas que podem ser adotadas frente às dificuldades dos pacientes e dos membros da equipe.

A prevalência de depressão/angústia referida na literatura para pacientes submetidos ao TMO é condizente com outros estudos sobre populações gerais de pacientes com câncer. Temos observado, entre- tanto, aparentemente, maior prevalência de sintomas ansiosos nos pacientes transplantados, com queixas de insônia inicial e angústia. Notamos também que os pacientes que se mostram calmos, tranqüilos, com certo conhecimento prévio da sua doença e da terapêutica, sem alterações da personalidade, apresentam boa resposta adaptativa durante a fase de internação e seguimento ambulatorial, enquanto aqueles com alterações significativas na personalidade necessitam de acompanhamento psiquiátrico ambulatorial mais freqüente, com introdução de psicofármacos para tratamento dos sintomas depressivos e ansiosos. Infelizmente, por falta de um protocolo de acompanhamento propectivo, não foi possível correlacionar estes perfis comportamentais com complicações ou resultados globais do TMO. Esta correlação foi feita na literatura ${ }^{(17 a, b, c)}$ e corrobora nossa impressão de que, quanto mais o paciente consegue compreender o que está ocorrendo com ele e quanto mais participativo se torna no tratamento, maiores são suas chances de ter um resultado favorável no transplante.

\section{2- ENFOQUE PSICOLÓGICO DO TMO DO PONTO DE VISTA DO PACIENTE}

O Transplante de Medula Óssea (TMO) representa para o paciente uma perspectiva de cura após o diagnóstico de uma doença grave e potencialmente fatal, como as leucemias agudas, a mielóide crônica, os linfomas, o mieloma múltiplo e a anemia aplástica grave, dentre outras.

Essa possibilidade de cura instila esperança no paciente e na família, amenizando os sentimentos dolorosos provocados pelo impacto do diagnóstico. A despeito dos avanços recentes no tratamento oncológico, não há garantias de que a intervenção terá êxito, já que há sempre a possibilidade de que, mesmo que o transplantado sobreviva à fase precoce mais complicada do procedimento, a doença básica recaia ou surjam novas doenças, como a do enxerto-contrahospedeiro (DECH), que tem significativa mortalidade e, principalmente na forma crônica, diminui sensivelmente a qualidade de vida do paciente. Nesse contexto de incertezas quanto aos resultados da intervenção, a esperança contribui para que o paciente oncológico e seus familiares suportem as difíceis fases da experiência de tratamento e recuperação.

Normalmente, há uma espera de semanas a meses entre o diagnóstico da doença básica, a investigação de possíveis doadores e o início do TMO. Quando o paciente chega ao hospital para submeter-se ao proce- 
dimento, diversas etapas já foram percorridas neste caminho, que implicam em uma série de importantes experiências vividas pelo então candidato ao transplante.

Para compreender a perspectiva do paciente, é necessário, em um primeiro momento, deixar de lado os saberes técnicos a respeito da doença, do tratamento e de suas conseqüências. Esses saberes, sistematizados pela ciência onco-hematológica, são fundamentais para o embasamento da prática profissional da equipe de saúde, contudo, também podem contribuir para que o profissional lance um olhar mais distanciado para o paciente, focalizando sua atenção sobre a doença em detrimento do sujeito. É preciso considerar que, apesar da especificidade da intervenção oncológica, existem respostas subjetivas do paciente ao diagnóstico e ao tratamento que interferem no seu resultado. A abordagem psicológica do paciente oncológico mostra os perigos de se tomá-lo somente como um ser doente, $\mathrm{e}$ não como uma pessoa portadora de uma doença, esquecendo-se de que muitas de suas potencialidades não foram comprometidas pelo adoecer.

A perspectiva do paciente, quando entra em contato com o ambiente hospitalar, é marcada por sentimentos de estranheza e perplexidade. Afinal, ele está fora de seu habitat doméstico, momentaneamente excluído de seu território familiar e atravessará momentos de intenso sofrimento físico e emocional, em situações que podem prolongar ou abreviar sua vida nesse novo e desconhecido ambiente. Ao chegar à unidade hospitalar, já fragilizado pela doença e impactado pelo diagnóstico, o paciente se vê diante do desconhecido. Decorrido algum tempo, é comum ouvir deles que se sentiram "perdidos" nesse momento, como se tivessem caído "numa terra de estrangeiros". O segundo choque que experimentam é ver o próprio corpo manipulado por instrumentos e procedimentos invasivos, comandados por pessoas estranhas portadoras de estranhos códigos e todo um aparato técnico inassimilável do ponto de vista do paciente, do qual se espera que se submeta docilmente às intervenções. Uma paciente, por exemplo, relata a experiência de horror e desamparo que vivenciara nesse momento. Os sentimentos de medo, horror e desalento só foram abrandados no momento em que ela pôde reconhecer um rosto familiar em meio aos desconhecidos que dela se acercavam.

Para minimizar esse sentimento de estranheza que o paciente vivencia frente ao desconhecido, é importante compreender o modo como foi constituída sua subjetividade, ou seja, sua maneira peculiar de se colocar no mundo e enfrentar as situações adversas. Esse modo peculiar de responder às solicitações desafiadoras do meio e da própria realidade psíquica está inscrito em seu repertório de defesas psicológicas, moldado ao longo do processo de desenvolvimento de cada indivíduo. É por isso que a maneira do paciente entender as orientações e informações médicas não depende apenas de suas habilidades cognitivas, mas passa necessariamente por sua individualidade, seu sistema de valores e normas culturais internalizadas. Assim, cada paciente exigirá uma estratégia única de abordagem e da sua comunicação e seu sofrimento.

Esta situação nos coloca, enquanto profissionais de saúde, constantemente frente ao novo, ao inusitado de cada encontro, já que, para cada indivíduo, devemos criar uma maneira de nos comunicar com seu mundo interno para que possamos atingir juntos paciente e profissional - o objetivo que nos une: o bom andamento do tratamento. Vamos examinar esta aboradagem nas três fases do transplante (antes, durante e depois do procedimento).

\subsection{Antes do transplante}

Frente ao diagnóstico, o paciente pode experimentar uma diversidade de reações, com nuances que variam de acordo com seu padrão de enfrentamento de situações estressantes. Pode sentir medo do sofrimento físico, raiva por necessitar de um tratamento tão arriscado que não lhe garante a cura, ou então pode sentir-se perplexo e chocado, impossibilitado de pensar no futuro ${ }^{(18)}$. O desencadeamento desses sentimentos ameaçadores pode ser ilustrado pela percepção do momento do diagnóstico elaborada por uma paciente com leucemia aguda bifenotípica:

"Naquele momento em que a médica falava as palavras sobre a doença, eu senti um buraco escuro se abrindo no meu peito. Ela me falava das células e do tratamento e eu queria sair correndo da sala." (Sonia, 23 anos, amasiada).

Avaliações psicológicas pré-transplante têm evidenciado correlações entre estilo de enfrentamento passivo com distúrbios de afeto e outras psicopatologias ${ }^{(18 a)}$ e a possibilidade de prever a ocorrência de problemas emocionais pós-transplante com o uso de escalas de rastreamento ${ }^{(18 b)}$.

\subsubsection{Trabalhando com a esperança}

Se, por um lado, diante do diagnóstico de uma doença potencialmente fatal, o sentimento do paciente é mediado pela incerteza quanto ao futuro, por outro lado, coexiste a capacidade de depositar esperan- 
ça na possibilidade de cura, mesmo que esta exija percorrer um longo processo de tratamento. Essa situação envolve as dimensões afetiva, social, física e espiritual, reunidas nos fundamentos da bioética ${ }^{(18)}$.

A esperança é particularmente importante para pessoas diagnosticadas com doenças limitantes da qualidade de vida (vide secção 3). Clínicos e pesquisadores descrevem a esperança como favorecedora da qualidade de vida, influenciando positivamente o curso da doença ou da desordem somática. Assim, segundo a American Cancer Society ${ }^{(19)}$, o câncer é uma das doenças em cuja evolução a esperança de cura desempenha papel fundamental. A esperança pode ser definida como sendo o ponto mais profundo dirigido ao enriquecimento do ser, conseguindo mobilizar no indivíduo uma força de vida que facilita a perseverança no alcance do objetivo esperado ${ }^{(20,21)}$. O indivíduo que tem esperança parece agir com mais otimismo, $o$ que facilita a compreensão de suas necessidades e deveres.

A falta de esperança é uma das quatro formas de enfrentamento apresentadas por paciente portadores de melanoma, sendo considerada a menos adaptativa delas ${ }^{(22)}$. As outras três formas de enfrentamento são: a negação, o estoicismo e o espírito de luta, sendo esta última a mais adaptativa. Observouse em um estudo que pacientes que exibiam o espírito de luta como mecanismo principal de enfrentamento apresentaram prolongamento da sobrevida e que, dos pacientes que freqüentavam um grupo de auto-ajuda, $66 \%$ apresentaram esse mecanismo de forma preponderante, o que redundava em uma busca mais ativa de tratamento para si e maior questionamento dos procedimentos utilizados. Dentro desse grupo, foi verificado que $31 \%$ dos pacientes que não utilizavam o espírito de luta passaram a empregá-lo após a frequiência ao grupo ${ }^{(23)}$.

\subsubsection{Grupo de pacientes que aguardam o TMO}

A literatura tem salientado a importância de se proporcionar, ao paciente com indicação ao TMO, um trabalho de preparação mais intensivo no período prétransplante, visando a informar, identificar, prevenir e intervir precocemente nas complicações que podem resultar das mudanças drásticas na situação de vida desses pacientes ${ }^{(24)}$. Essa intervenção deve buscar meios de integrar o paciente à equipe, com o objetivo de torná-lo simultaneamente parte e sujeito de seu tratamento. Uma das maneiras encontradas para que essa integração passasse a ocorrer foi o fornecimento de informações adequadas às questões que a experiên- cia do paciente e as suas necessidades suscitam. Outra maneira complementar foi promover o intercâmbio de informações entre pacientes que se encontravam na mesma situação de vida ${ }^{(25)}$.

$\mathrm{Na}$ Unidade de TMO do HCFMRP-USP, observou-se que, apesar dos médicos fornecerem, durante as consultas preliminares, repetidas e detalhadas informações sobre todo o processo, seus riscos e consequiências, após a internação muitos pacientes manifestavam dúvidas e desconhecimentos que prejudicavam sua adesão ao tratamento e, por consegüinte, comprometiam sua colaboração nas fases mais complicadas do TMO. Através de um levantamento, executado pelo serviço de psicologia da Unidade, constatou-se que, mesmo informados de maneira sistemáti$\mathrm{ca}$, os pacientes deixavam de expor suas dúvidas e fornecer informações importantes sobre suas condições clínicas e psicossociais. Pensou-se, então, que talvez isso pudesse ser transformado, oferecendo-se ao paciente, na etapa pré-TMO, um contato mais intenso com a instituição de saúde e seu profissionais.

Unindo essa constatação aos achados da literatura $^{(23,24)}$, optou-se por introduzir, em caráter experimental, uma nova modalidade de atendimento psicológico, tendo o dispositivo grupal como eixo norteador. Constituiu-se um grupo de pacientes que aguardavam o procedimento do TMO, visando intensificar o preparo para a internação e a melhoria da qualidade de vida antes, durante e depois do transplante.

Uma análise sistemática dos resultados obtidos evidenciou que o grupo de pacientes emergiu como uma estratégia adequada para responder às necessidades do indivíduo em situação de espera do TMO. Esse procedimento de intervenção parece favorecer a integração com a equipe de saúde durante a internação e a adaptação inicial pós-TMO, mobilizando a busca de recursos pessoais na resolução dos problemas deflagrados pela situação de crise, colaborando assim para que os pacientes procurem antecipar sua volta às atividades produtivas e sociais ${ }^{(25)}$.

Os resultados da intervenção foram percebidos pela enfermagem e pela equipe médica, sobretudo, através da mudança de atitude dos pacientes, que se tornaram mais ativos durante seu período de hospitalização e mais conscientes de suas limitações e de suas possibilidades de reabilitação após o transplante. Nessas condições, o grupo da fila de espera destaca-se como uma boa opção de intervenção, que atua tanto no sentido psico-profilático, prevenindo o surgimento, agravamento ou cronificação de problemas psicológicos, como no sentido de criar formas de 
enfrentamento para o paciente diante de sua vulnerabilidade física e emocional provocada pela quimio/radioterapia em altas doses e suas consequiências.

Para melhor ilustrar essa intervenção, destacamos a fala de um paciente entrevistado acerca de sua participação no grupo acima apresentado ${ }^{(26)}$.

"Acho que foi muito bom ver as pessoas jovens como eu esperançosas e com força para enfrentar a barra do TMO. Ficava um pouco triste por saber que, daquelas pessoas, umas não iriam resistir. Mas é bom receber as informações, saber o que vai acontecer na internação, saber que o TMO é complicado. Se a pessoa vai achando que vai ficar boa logo, é aí que não dá certo." (Geraldo, 29 anos, casado, portador de leucemia mielóide aguda).

\subsection{Durante o transplante}

Apesar da sua simplicidade e brevidade, do ponto de vista técnico, a infusão da medula óssea (ou de outro produto transplantado) é um dos momentos mais significativos de todo o procedimento, para o paciente e sua família. Eles experimentam, naquelas poucas horas da infusão, intenso grau de emoção, que é gerado, principalmente, pela esperança de cura produzida pela transferência física das células do doador ao receptor. Membros da equipe não devem minimizar o significado simbólico do ato de infusão das células, mas aproveitá-lo para influir positivamente no ânimo e na colaboração do paciente.

$\mathrm{O}$ isolamento protetor (utilizado para proteger o paciente de infecções), os efeitos colaterais da quimio/ radioterapia (náuseas, vômitos, fraqueza, alterações corporais, mucosite, dentre outros), somados à morosidade do tratamento e da melhora física, trazem uma realidade de sofrimento emocional, psíquico e físico ao paciente e seus familiares. O paciente precisa do máximo de ajuda possível para que possa cooperar com seu próprio tratamento diante dessa experiên$\operatorname{cia}^{(27)}$.

O estresse físico e emocional é desencadeado por diversos fatores. Em primeiro lugar, um tratamento tão doloroso, que é suportado pela esperança de cura, não garante que o sofrimento seja recompensado ao final, ou seja, o paciente passa por todo o processo sem a garantia da cura. Essa incerteza colabora para o aumento da ansiedade frente aos sintomas desagradáveis e o temor de que o "pior possa acontecer". A capacidade de suportar situações de estresse metabólico e emocional é muito variável e, muitas ve- zes, incompreensível para a equipe de saúde, que nem sempre está preparada para aceitar a fragilidade ou a força demonstrada por alguns pacientes diante do sofrimento.

Nessas situações, o apoio psicológico deve ser intensificado, visando abarcar o paciente, a família e a equipe de saúde, incluindo o psicólogo. As opções de intervenção psicológica nessa fase devem basear-se numa avaliação clara das necessidades e possibilidades do paciente e devem ser individualizadas conforme o quadro clínico. $\mathrm{O}$ atendimento psicoterápico no leito constitui uma boa alternativa para os pacientes. Para os familiares, opta-se por atendimentos sistemáticos em grupo e, dependendo da necessidade, o familiar é atendido individualmente. No caso de crianças e adolescentes, sugere-se que a família seja atendida com a frequiência mínima de uma vez por semana.

\subsection{Após o transplante}

Depois de realizado o transplante, observa-se que a qualidade de vida dos pacientes sofrerá as implicações decorrentes do procedimento. Eles são obrigandos a enfrentar as limitações físicas, a dor, a sensação de distorção da imagem corporal e as consequiências dos efeitos colaterais dos tratamentos, como queda de cabelo, escurecimento da pele, emagrecimento ou edema, além das alterações nos seus hábitos de vida, tais como a perda ou prejuízo da capacidade produtiva (no trabalho e na escola), das funções sexuais e da fertilidade (como efeito colateral de algumas modalidades de quimio ou radioterapia), bem como a perda da independência e de alguns papéis sociais ${ }^{28)}$. Alguns casos podem evoluir para o quadro clínico da doença do enxerto-contra-hospedeiro $(\mathrm{DECH})$, aguda ou crônica, com alta morbi-mortalidade e prejuízo da qualidade de vida.

As dificuldades de adaptação fora do contexto hospitalar impõem a necessidade de uma continuidade do cuidado integral, que inclui uma intervenção psicológica após a alta da enfermaria. Essa intervenção ocorre, em nosso contexto, através de suporte psicológico fornecido em nível ambulatorial. Esse suporte corresponde a atendimentos individuais, que visam a manter a continuidade do atendimento da enfermaria até completados os cem dias pós-TMO. Esses atendimentos são realizados ambulatorialmente $\mathrm{e}$ sua freqüência varia em função da necessidade de cada paciente. Encerrado o período dos cem dias, quando o paciente geralmente retorna a seu lar, opta-se pela alta do atendimento psicológico, pelo retorno livre (no qual o paciente pode recorrer ao atendimento quan- 
do sentir necessidade) ou por um encaminhamento para outro serviço que preste assistência psicológica.

Um paciente fez o seguinte relato, durante um atendimento psicoterápico, quando se encontrava prestes a receber alta da enfermaria, após ser submetido ao TMO:

"Quando entrei no hospital para fazer a primeira quimioterapia, senti que precisava escalar uma montanha com as mãos. Depois de todo o trabalho que nós realizamos, o grupo, o atendimento aqui no quarto, o apoio que você deu para a minha mulher, eu senti que pude escalar a mesma montanha com equipamentos de alpinismo." (Geraldo, 29 anos, casado, portador de leucemia mielóide aguda).

Esse relato é capaz de demonstrar, em poucas palavras, o efeito do suporte psicológico como um elemento coadjuvante no tratamento e na reabilitação psicossocial do paciente oncológico submetido ao TMO. Os resultados dos estudos disponíveis oferecem evidências empíricas que reforçam a importância desse trabalho na melhoria da qualidade de vida dos pacientes ${ }^{(29)}$, que inevitavelmente necessitam de passar por transições psicossociais ${ }^{(30)}$ para potencializar seus recursos de enfrentamento da nova condição introduzida pela enfermidade e seu tratamento.

\section{3- AVALIAÇÃO DA QUALIDADE DE VIDA APÓS O TMO}

Em geral, as pesquisas realizadas sobre qualidade de vida pós-TMO têm estudado grupos extensos de sujeitos avaliados através de instrumentos específicos como escalas, questionários e entrevistas ${ }^{(31 / 34)}$. Estes estudos têm apontado para padrões adaptativos gerais, avaliando principalmente os indicadores externos de adaptação, que poderiam refletir as condições internas e os recursos pessoais dos sobreviventes de TMO. Não foram encontrados na literatura estudos que avaliem os recursos pessoais internos para a adaptação, combinando instrumentos variados, incluindo técnicas projetivas. Elas envolvem conteúdos diferenciados que permitem uma compreensão ampla e aprofundada das características de personalidade de pacientes submetidos ao TMO.

\subsection{Técnicas de avaliação ${ }^{(35)}$}

Considerando-se a importância do ajustamento desses pacientes sob o enfoque dos recursos psicoló- gicos, bem como a escassez de pesquisas que utilizam técnicas projetivas como métodos de avaliação, investigamos as condições psicológicas e a qualidade de vida de dez pacientes adultos submetidos ao TMO no HCFMRP, através de entrevistas, escalas e técnicas projetivas, considerando dois momentos distintos de recuperação - adaptação inicial (seis ou sete meses pós-TMO, Grupo 1) e adaptação a médio prazo (2153 meses, pós-TMO, Grupo 2). Todos os pacientes realizaram transplante alogênico, sendo seis pacientes transplantados com diagnóstico inicial de Leucemia Mielóide Crônica e quatro pacientes com Anemia Aplástica Severa. Observou-se um predomínio de baixo nível de escolaridade, bem como atividades profissionais de pouca qualificação, estando a maioria inativa no momento da avaliação ${ }^{(35)}$.

Para a coleta de dados, foram utilizados os seguintes instrumentos: a) Questionário de História Vital, abordando dados de identificação, situação clínica atual, dados familiares e desempenho social; b) Questionário sobre Qualidade de Vida e Recuperação, com base nas proposições de Haberman et al. ${ }^{(36)}$, abordando questões relativas ao estado geral de saúde, à execução de atividades diárias, à adaptação social e às expectativas quanto ao futuro; c) Questionário de Auto-Avaliação - IDATE (Ansiedade Traço - Estado) - Parte I/II, traduzido e padronizado para o nosso meio por Biaggio et al. ${ }^{(37)}$; d) Escala Multidimensional de Locus de Controle de Levenson, que busca explicar a percepção das pessoas sobre a fonte de controle dos acontecimentos em que são envolvidas, tendo sido traduzida e padronizada por Dela Coleta ${ }^{(38)}$; e) Escala de Ansiedade $e$ Depressão para Hospital Geral, desenvolvida para estimar a prevalência de transtornos do humor em pacientes adultos com afecções físicas, em ambientes não psiquiátricos, traduzida e adaptada por Botega et al. ${ }^{(39)}$; f) Técnica de Rorschach, instrumento projetivo que permite uma avaliação mais profunda da personalidade. Utilizou-se a nomenclatura francesa de Traubenberg ${ }^{(40)}$ e os padrões normativos de Augras ${ }^{(41)}$; g) Técnica do Desenho da Figura Humana $(D F H)$, conforme as proposições de Van $\mathrm{Kolck}^{(42)}$. Através da representação gráfica do DFH, buscou-se apreender a imagem corporal que pacientes transplantados de medula óssea possuem de si, bem como identificar suas necessidades e conflitos.

Com base nestes instrumentos de avaliação, procedemos a uma análise dos aspectos psicológicos e da qualidade de vida dos pacientes, buscando-se compreender a maneira como os sujeitos, ora analisados, 
têm investido seus recursos pessoais para responder às complexas demandas do meio frente à situação de TMO. Para atingir estes objetivos, resumiremos a seguir as principais contribuições de cada instrumento.

As entrevistas, além de terem favorecido estabelecer o vínculo pessoal pessoal com o paciente (rapport), permitiram o conhecimento, referido pelos sujeitos, da sua história de vida e dos padrões adaptativos prévios, instrumentando melhor as interpretações das outras técnicas. As escalas, por sua vez, possibilitaram a identificação dos recursos disponíveis à capacidade adaptativa dos sujeitos, comparativamente aos grupos controles, bem como a identificação de dificuldades no momento atual, sugerindo que os pacientes com mais tempo pós-TMO se percebem com mais recursos de controle sobre os eventos. As técnicas projetivas de Rorschach e do desenho da figura humana destacaram-se como instrumentos que permitiram uma compreensão aprofundada da personalidade em suas múltiplas dimensões, como será discutido abaixo.

\subsection{Análise dos testes projetivos}

Pode-se observar, através da Técnica de Rorschach, que a percepção dos sujeitos frente ao ambiente tende a ser generalista, com limitações na verificação dos elementos essenciais dos fatos, evitando que aspectos mais pessoais e indesejados interfiram na sua conduta. É provável que a necessidade de se estabelecer um contato mais superficial com o ambiente esteja relacionada a uma intensa sensibilidade aos estímulos afetivos intrínsecos, que parecem não estar sendo elaborados, tendendo, assim, à pouca utilização dos recursos pessoais. Esta situação se expressa por indicadores que denotam sentimentos de angústia e ansiedade frente às situações vitais, acompanhados por sentimentos de inadequação e desconforto emocional, associados a uma franca dificuldade em se confrontarem com conteúdos conflitivos.

Como hipótese, pode-se pensar que tal funcionamento afetivo esteja associado ao fato de a maioria dos pacientes aqui avaliados não haverem superado, por inteiro, o impacto psicológico trazido pela experiência de TMO, a qual, possivelmente intensificou as características prévias de inibição da personalidade como forma de garantir uma maior capacidade adaptativa. Desse modo, os recursos intelectuais não se encontram disponíveis para a criatividade e construção, estando voltados, essencialmente, para a manutenção do funcionamento da personalidade. Tais limitações, expressas por atitudes de isolamento, fecha- mento e estereotipia, são reforçadas pelos dados da história vital. Assim, é possível hipotetizar que faltam aos sujeitos, ora analisados, elementos para elaboração e integração de tais experiências, observando-se uma construção emocional frágil, caracterizando a vivência de uma situação de crise com um certo grau de insatisfação frente a não canalização afetiva das necessidades. Dessa forma, pode-se supor que, se forem motivados adequadamente, estes pacientes poderão usufruir melhor de sua energia psíquica em favor de uma adaptação mais efetiva com o ambiente, bem como auferir maior satisfação pessoal. Não se observam, através da técnica de Rorschach, diferenças marcantes entre os dois grupos estudados (de curto e médio prazos após o TMO), apesar dos dados não terem sido analisados estatisticamente.

Outro ponto a ser destacado diz respeito à autoimagem. Os estudos relativos aos aspectos clínicos e psicossociais em pacientes pós-TMO têm identificado, como áreas principais de deficiência potencial, o desempenho em atividade física vigorosa e a insatisfação com a aparência física ${ }^{(43,44,45)}$. Considerando as possíveis complicações físicas e psicossociais enfrentadas por pacientes pós-TMO, partimos, inicialmente, da hipótese de que os pacientes do Grupo 1 apresentariam uma maior alteração na auto-imagem, devido ao TMO ser mais recente, cuja condição impõe uma maior vulnerabilidade a infecções e uma certa limitação ao funcionamento físico, associada com alterações da aparência pessoal, remanescentes, ainda, do tratamento quimioterápico e imunossupressor. Em contrapartida, os pacientes do Grupo 2 teriam uma auto-imagem menos comprometida, pelo fato de, geralmente, não apresentarem debilidade física e terem superado as alterações na aparência pessoal. Nesse sentido, a técnica gráfica do DFH parece confirmar a hipótese de que os pacientes do Grupo 1 estariam mais afetados pelo transplante do que os pacientes do Grupo 2, uma vez que os pacientes do Grupo 1 remeteram-se a figuras mais jovens, ao representá-las graficamente. (Figura 1) ${ }^{(46)}$. Nesse sentido, o distanciamento das vivências atuais e o voltar-se para vivências prévias - mais presente no Grupo 1 - sugere que o tempo constituiu-se em uma variável que interfere no processo adaptativo, favorecendo-o de forma a garantir uma auto-imagem mais preservada e integrada nos pacientes com seguimento mais longo (grupo 2) e que a representação gráfica da figura humana mostrou-se sensível para refletir estas mudanças clínicas. É importante destacar ainda que a variável temporal, 

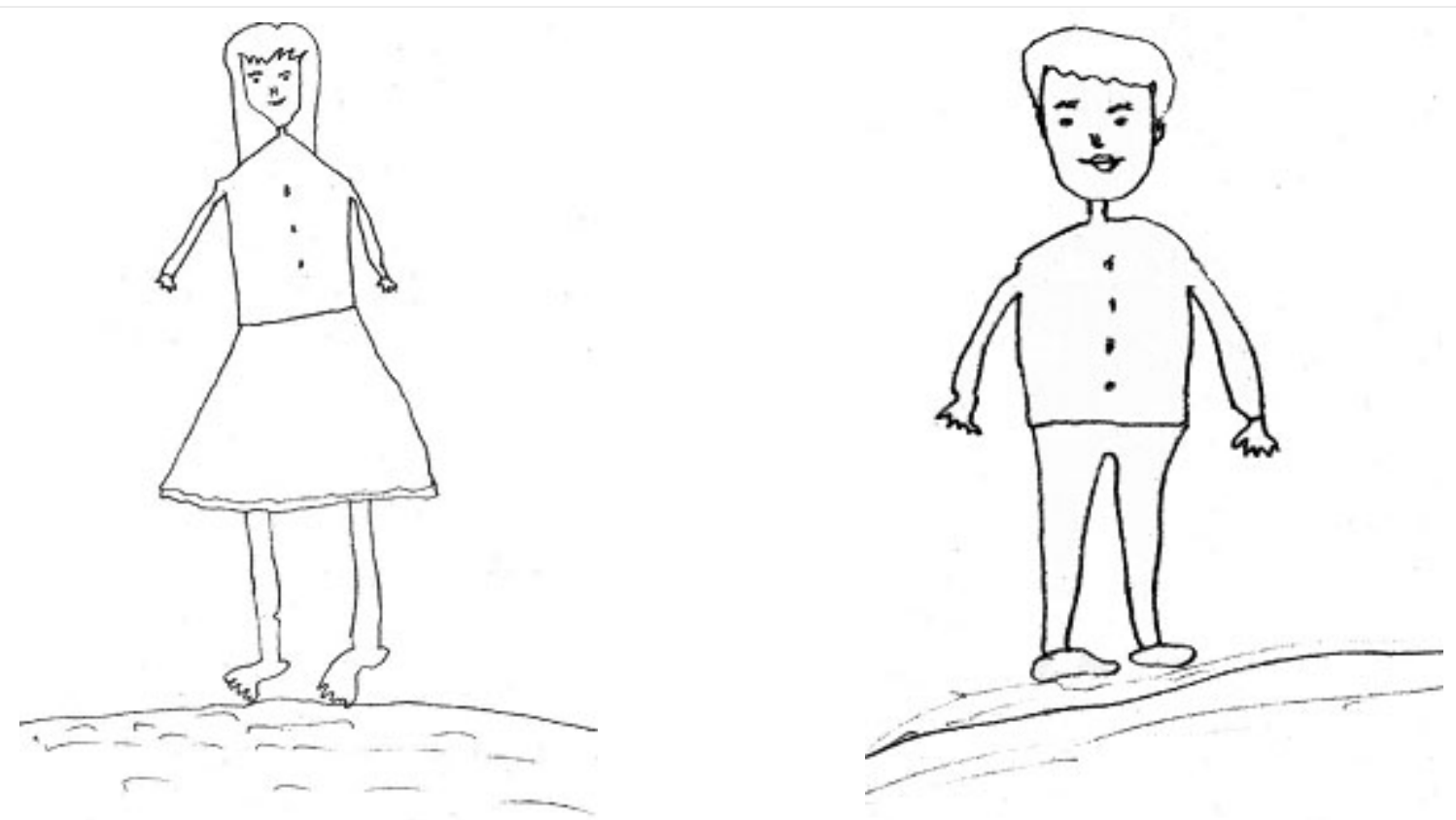

Figura 1: Desenho da figura humana feito pelo paciente B do grupo 1, do sexo masculino, solteiro, com 19 anos de idade e escolaridade de segundo grau incompleto, procedente do interior da Bahia, vendedor, inativo no momento da avaliação, transplantado há 6 meses para leucemia mielóide crônica em fase crônica. Neste teste, o paciente é solicitado a desenhar a própria figura e outra do sexo oposto. Nota-se a predominância de aspectos infantis e imaturos (figuras muito jovens, presença de botões, ênfase no contorno da roupa), sugerindo a instabilidade do sujeito ao nível de suas vivências mais profundas (figura nas pontas dos pés, linha do solo acentuada). Apresenta ainda alguns indicadores de conflito, denotando sentimentos de angústia e ansiedade frente a situações vitais (sombreamento, pernas longas e finas), bem como insatisfação quanto à auto-imagem (sexo oposto desenhado em primeiro lugar). Mostra dificuldade nos relacionamentos interpessoais (sombreamento e reforço no contorno facial, pupila sem óbita no olho), experimentando sentimentos de inadequação e dependência (mãos pequenas, queixo bem pronunciado, braços curtos, fracos e finos, pendentes ao longo do corpo). A integração desta análise sugere uma imaturidade afetivo-social, experimentando frustração e fraqueza na manipulação do ambiente, o que pode estar relacionado ao impacto da experiência do TMO sobre o seu momento atual de vida, dificultando o seu amadurecimento. Reproduzida da ref ${ }^{(46)}$.

analisada nesse estudo, sugere que pacientes clinicamente bem sucedidos trazem, implicitamente, a idéia de terem recursos psicológicos relativamente bem ajustados, mas não é possível dissecar a relação de causa e efeito entre o sucesso do transplante e o ajustamento psicológico.

\subsection{Análise integrada da qualidade de vida}

$\mathrm{Na}$ avaliação da qualidade de vida, as expectativas dos pacientes, antes da realização do TMO, assumem um papel relevante no seu ajustamento psicológico ${ }^{(36,45)}$. No presente estudo, pôde-se observar que todos os sujeitos - exceto um do Grupo 2 - relataram expectativas bastante otimistas em relação ao TMO, percebendo-o como sua única chance de cura. Entretanto, alguns sujeitos pareceram subestimar o risco desse procedimento, ao afirmarem que "nunca tiveram dúvida" de que ele daria certo. Essa visão do
TMO como uma restauração completa da saúde, com um retorno conseqüente à normalidade, sugere uma atitude basicamente defensiva frente à situação de ameaça na qual se encontram, em que a negação do risco de mortalidade os protegeria de uma realidade difícil de aceitar. Nesse sentido, Andrykowski ${ }^{(45)}$ salienta a dificuldade de se avaliar a influência real das expectativas no processo de se submeter ao TMO, dadas as circunstâncias em que tal decisão é tipicamente feita.

O conceito de qualidade de vida precisa ser adaptado ao contexto social e à história vital de cada paciente, bem como aos seus recursos potenciais para obter uma maior satisfação pessoal. Nessa perspectiva, buscou-se avaliar a capacidade adaptativa do paciente, considerando-se as diferenças individuais, a partir das quais foi possível contextualizar o impacto da experiência de TMO na vida de cada sujeito, toman- 
do-se como referência a integração das diferentes técnicas de avaliação. Esta integração foi realizada de acordo com Wellish \& Wolcott ${ }^{(47)}$, os quais, visando predizer a adaptação psicológica e o enfrentamento no processo de TMO, desenvolveram medidas sistemáticas para classificar o ajustamento psicossocial dos pacientes em três níveis, bom (nível I), regular (nível II) e pobre (III) (Tabelas II e III).
No presente estudo, a maioria dos pacientes valorizava a saúde como o fator mais importante na qualidade de vida, reportando problemas reais, como efeitos colaterais de drogas e complicações do transplante e o medo de recidiva da doença ou de uma sobrevida mais curta, como decorrência do tratamento. Nesse sentido, a análise integrada dos dados sugeriu que o impacto negativo do TMO é mais atribuído à

Tabela II- Níveis de Ajustamento Psicossocial de Pacientes Pós-TMO*

\begin{tabular}{|c|c|c|c|}
\hline $\begin{array}{l}\text { Características } \\
\text { Psicossociais }\end{array}$ & $\begin{array}{l}\text { Nível I } \\
\text { Bom }\end{array}$ & $\begin{array}{l}\text { Nível II } \\
\text { Regular }\end{array}$ & $\begin{array}{l}\text { Nível III } \\
\text { Pobre }\end{array}$ \\
\hline $\begin{array}{l}\text { 1- História } \\
\text { psiquiátrica } \\
\text { anterior }\end{array}$ & Nenhuma & $\begin{array}{l}\text { Alquma história de depressão, } \\
\text { ansiedade ou trauma; tracos de } \\
\text { distúrbio de personalidade; } \\
\text { alquma história de perda } \\
\text { significativa. }\end{array}$ & $\begin{array}{l}\text { História de dependência } \\
\text { química; perdas múltiplas ou } \\
\text { significativas; qrave distúrbio } \\
\text { de personalidade; grave } \\
\text { distúrbio de ansiedade ou } \\
\text { fobias;depressão maior. }\end{array}$ \\
\hline $\begin{array}{l}\text { 2- Qualidade de } \\
\text { suporte } \\
\text { familiar/ social }\end{array}$ & $\begin{array}{l}\text { De bom a excelente: } \\
\text { membros da família/ meio } \\
\text { social presentes e } \\
\text { disponíveis; dispostos a } \\
\text { reconhecerem as } \\
\text { necessidades do paciente. }\end{array}$ & $\begin{array}{l}\text { De bom a regular: alguma } \\
\text { dificuldade de separação; algum } \\
\text { conflito e problemas de } \\
\text { dependência. }\end{array}$ & $\begin{array}{l}\text { Disfuncional: envolvimento } \\
\text { limitado; conflitos intensos; foco } \\
\text { nas necessidades individuais } \\
\text { dos familiares às custas do } \\
\text { paciente. }\end{array}$ \\
\hline $\begin{array}{l}\text { 3- História prévia } \\
\text { de enfrentamento }\end{array}$ & $\begin{array}{l}\text { De boa a excelente: } \\
\text { capacidade de adaptação aos } \\
\text { problemas e mudanças; } \\
\text { repertório de } \\
\text { comportamentos de } \\
\text { enfrentamento. }\end{array}$ & $\begin{array}{l}\text { De boa a reqular: alquma } \\
\text { flexibilidade no repertório de } \\
\text { enfrentamento, ou seja, alqumas } \\
\text { variacõos nas respostas de } \\
\text { enfrentamento, com limitações } \\
\text { gerais; algum padrão negativista } \\
\text { de respostas em situações de } \\
\text { estresse }\end{array}$ & $\begin{array}{l}\text { De regular a pobre: } \\
\text { descompensação em situações } \\
\text { de estresse; padrões } \\
\text { neqativistas; estilo ríaido; } \\
\text { história de comportamentos } \\
\text { auto-destrutivos; repertório } \\
\text { pobre de enfrentamento; } \\
\text { respostas impulsivas ou } \\
\text { agressivas. }\end{array}$ \\
\hline $\begin{array}{l}\text { 4- Enfrentamento } \\
\text { da doença e } \\
\text { tratamento }\end{array}$ & $\begin{array}{l}\text { Resolução de sentimentos } \\
\text { relacionados ao diagnóstico; } \\
\text { considerar opções de } \\
\text { tratamento baseando-se na } \\
\text { realidade. }\end{array}$ & $\begin{array}{l}\text { Negação; ambivalência na } \\
\text { escolha do tratamento. }\end{array}$ & $\begin{array}{l}\text { Negação extrema; confusão no } \\
\text { curso da doença; grave } \\
\text { ambivalência quanto ao } \\
\text { tratamento. }\end{array}$ \\
\hline $\begin{array}{l}\text { 5- Qualidade do } \\
\text { afeto }\end{array}$ & $\begin{array}{l}\text { Sentimentos de medo e } \\
\text { tristeza apropriados; alquma } \\
\text { ansiedade. }\end{array}$ & $\begin{array}{l}\text { Sentimentos de medo e } \\
\text { ansiedade moderados; } \\
\text { depressão moderada. }\end{array}$ & $\begin{array}{l}\text { Ansiedade generalizada; } \\
\text { depressão moderada ou } \\
\text { severa; intensos sentimentos } \\
\text { de medo e raiva. }\end{array}$ \\
\hline $\begin{array}{l}\text { 6- Estado mental } \\
\text { (passado e } \\
\text { presente) }\end{array}$ & $\begin{array}{l}\text { Nenhum prejuízo cognitivo; } \\
\text { ciclo de sono preservado; } \\
\text { nível normal de atividade. }\end{array}$ & $\begin{array}{l}\text { Alquma história, passada ou } \\
\text { atual, de prejuízo na função } \\
\text { cognitiva, atenção, ciclo de sono, } \\
\text { nível de atividade, } \\
\text { responsividade. }\end{array}$ & $\begin{array}{l}\text { Distúrbio global das funções } \\
\text { cognitivas } \\
\text { (percepção, pensamento, } \\
\text { memória, orientação); atenção; } \\
\text { ruptura severa do ciclo de } \\
\text { sono; nível de atividade } \\
\text { aumentado ou reduzido } \\
\text { (movimentos, fala). }\end{array}$ \\
\hline $\begin{array}{l}\text { 7- Predisposição } \\
\text { para ansiedade } \\
\text { antecipada }\end{array}$ & Nenhuma & $\begin{array}{l}\text { Moderada ou alta; ansiedade tem } \\
\text { início no dia da quimioterapia/ } \\
\text { irradiação. }\end{array}$ & $\begin{array}{l}\text { Grave ansiedade antecipada; } \\
\text { náuseas e vômitos começam } \\
\text { antes do dia de quimioterapia/ } \\
\text { irradiação. }\end{array}$ \\
\hline
\end{tabular}




\begin{tabular}{|lccc|}
\hline Tabela III - Análise integrada dos níveis de ajustamento psicossocial ao transplante de medula óssea \\
\hline \multicolumn{3}{|c|}{ Níveis de ajustamento } \\
\cline { 2 - 4 } Características psicossociais & Nível I & Nivel II & Nivel III \\
& Bom & Regular & Pobre \\
\hline 1. História psiquiátrica anterior & B, C & A, D, E & - \\
\hline 2. Qualidade de suporte familiar/social & 3,5 & 1,2 & 4 \\
\hline 3. História prévia de enfrentamento & C, B, E & D & A \\
\hline 4. Enfrentamento da doença e tratamento & $1,3,5$ & 4 & 2 \\
\hline 5. Qualidade do afeto & E & A, B, C, D & - \\
\hline 6. Estado mental (passado e presente) & 5 & 1,3 & 2,4 \\
\hline 7. Predisposição para ansiedade & 4,5 & B, D & A, C \\
\hline antecipatória & - & 1,2 & 3 \\
\hline *Casos A-E: 6-7 meses pós-TMO (Grupo 1) Casos $1-5: 21-53$ meses pós-TMO (Grupo 2) & A \\
\hline
\end{tabular}

sua repercussão sobre a atividade física e funcionalidade do paciente, em decorrência da redução do nível de energia, força e vigor, enquanto as relações sociais e afetivas, por sua vez, não são apontadas pela maioria como uma área de dificuldade. Assim, a auto-avaliação da qualidade de vida atual parece centrar-se nos aspectos físicos, em detrimento dos aspectos psicossociais. Tal atitude, provavelmente, está associada à própria concepção de que esses pacientes têm a cerca do que vem a ser qualidade de vida, lembrando que a condição sócio-econômica da maioria é bastante precária, mesmo antes do surgimento da doença, provavelmente favorecendo a percepção da qualidade de vida, de forma restrita, resumindo-se a ter saúde física.

É possível que a não retomada das atividades profissionais após o transplante, documentada na maioria dos sujeitos, que se encontrava ociosa e não buscava tarefas alternativas, reforce o sentimento de dependência dos familiares. Deve-se ressaltar, ainda, a importância que o trabalho exerce na reinserção social e no sentimento de identidade pessoal, lembrando que todos os pacientes estudados neste trabalho eram do sexo masculino, onde ocorre uma maior cobrança de atividade remunerada, relacionada ao papel de provedores de suas famílias. Ao trabalho também é facultada a possibilidade de uma organização da dinâmica psicológica interna ${ }^{(48)}$, constituindo um aspecto fundamental no processo de adaptação, representando, para alguns sujeitos, na condição de engajar-se num relacionamento afetivo, o que sugere que a auto-estima também está associada a uma atividade produtiva e remunerada. Nesse contexto, a preocupação, relatada pelos sujeitos, referente ao trabalho e à situação econômica, é um dado que converge com os da literatura, onde pesquisas realizadas com pacientes pós-TMO descrevem, como um dos significados do termo "qualidade de vida", o de ser capaz de trabalhar e obter sucesso financeiro ${ }^{(36,45,47,49)}$, enfatizando-se ainda o fato de a qualidade de vida estar diretamente relacionada à 
conservação de papéis sociais ${ }^{(17)}$. Por outro lado, é interessante notar que a maioria dos sujeitos não se reportam às atividades recreativas enquanto um aspecto básico na qualidade de vida; sendo possível supor, pela baixa condição sócio-econômica do grupo estudado, que essas atividades não eram uma preocupação premente, mesmo antes da realização do TMO.

Quanto aos recursos de enfrentamento pósTMO, a maioria dos sujeitos mostrava um estilo mais voltado à aceitação passiva dos limites impostos pelo tratamento, com atitudes de resignação sobrepondo-se a atitudes de luta. No entanto, pode ser observada também uma postura de colaboração ativa e uma boa adesão ao tratamento, bem como sentimentos de otimismo e esperança associados a uma avaliação positiva do TMO, o que pode ser um prenúncio de boa adaptação.

A adaptação social dos pacientes avaliados parece efetivar-se pela superficialidade dos contatos interpessoais, evitando um envolvimento pessoal, ativo e dinâmico, observando-se, como principal dificuldade dos sujeitos, a expressão de suas emoções de forma franca e direta. Todavia, apresentaram indícios sugestivos de uma de personalidade preservada, possibilitando-lhes efetuar esforços de adaptação. De um modo geral, dentro dos limites da casuística e dos instrumentos de avaliação, pode-se concluir que, através de uma análise integrada de diferentes testes de avaliação psicológica, foi possível caracterizar o padrão atual de adaptação de pacientes pós-TMO como diretamente relacionado aos recursos adaptativos prévios. Além disso, frente ao impacto do TMO, os mecanismos defensivos com base na inibição e restrição foram exacerbados como forma de ajuste, possivelmente protegendo os pacientes de outras vivências mobilizadoras de ansiedade e estresse. Nesse sentido, os dados obtidos podem facilitar práticas de intervenção e orientação que propiciem uma melhor qualidade de vida aos pacientes submetidos ao transplante de medula óssea.

CONTEL JOB; SPONHOLZ JR A; TORRANO-MASETTI LM; ALMEIDAAC; OLIVEIRAEA; JESUS JS; SANTOS MA; LOUREIRO SR \& VOLTARELLI JC. Psychological and psychiatric aspects of bone marrow transplantation. Medicina, Ribeirão Preto, 33: 294-311, july/sept. 2000.

ABSTRACT: The intensity and complexity involved in all levels of bone marrow transplantation (BMT) causes profound psychological effects on the patient, family and professional team. Ignoring this fact and reducing BMT issues to purely technical aspects may be catastrophical to the patients and his/her family and may challenge the survival of the program. In this work, three very important aspects of mental health in BMT are discussed: 1) multiple roles played by psychiatric assistance in BMT, from drug prescription through support of the team by group reflexion; 2) an analysis of emotions experienced by BMT patients in the different phases of transplantation (pre, intra- and post-) under the perspective of hope for cure ; 3 ) an evaluation of quality of life of patients submitted to BMT at medium and long terms, integrating various psychological instruments including projective techniques.

UNITERMS: Bone Marrow Transplantation. Psychology. Psychiatry. Stress. Psychotherapy, Group. Quality of Life.

\section{REFERÊNCIAS BIBLIOGRÁFICAS}

1 - COENSON C \& DIMSDALE JE. Psychiatric Liaison on Bone Marrow Transplantation Unit. Gen Hosp Psychiatry 16: 131134,1994

2 - WOLLCOTT D; WELLISCH D \& FAWZY F. Adaptation of adult bone marrow transplant recipients' long-term survivors. Transplantation 41:478-484, 1986.
3 - BAKER F; MARCELLUS D; ZABORA J; POLLAND A \& JOFREY D. Psychological distress among adults patients being evaluated for bone marrow transplantation. Psychosomatics 38: 10-19, 1997.

4 - JACOBSEN PB; WIDOWS MR; HANN DM; ANDRYKOWSKY MA; KRONISH LE \& FIELDS KK. Posttraumatic stress disorder symptoms after bone marrow transplantation for breast cancer. Psychosom Med 60: 366-371, 1998. 
5 - KLAPHEKE MM. The role of the psychiatrist in organ transplantation. Bull Menninger Clin 33: 13-39, 1999.

6 - HACKETT TP \& STERN TA. Suicide and other disruptive states.In: :Handbook of general hospital. Mosby, Year Book, St.Louis, p.281-307, 1991.

7 - DHOSSCHE DM. Suicidal behavior in psychiatry emergency room patients. South Medl J 93: 310-314, 2000.

8 - GOVES JE \& KUCHARSKI A. Brief Psychotherapy.. In: Handbook of general hospital. Mosby, Year Book, St.Louis, p.321-341, 1991.

9 - MURRAY GB. Confusion, Delirium, and Dementia.In: . Handbook of general hospital. Mosby, Year Book, St.Louis, p.89-120, 1991.

10 - STROUSE TB; EL-SADEN SM; GLASER NEM; BONDS C; AYARDS N \& BUSUTTIL RW. Immunosuppressant Neurotoxicity in Liver Transplant Recipients. Clinical challenges for the consultation-liaison psychiatrist. Psychosomatics 39: 124-33, 1998.

11 - CASSEM NH \& HACKETT TP. The setting of intensive care. IIn: Handbook of general hospital. Mosby, Year Book, St.Louis, p.373-399, 1991.

12 - STAHL SM. Psychopharmacology of antidepressants. , Martin Dunitz, London, 1997.

13 - HYMAN SE \& TESAR GE. Agitation and delirium. In: TESAR GE. Manual of psychiatric emergencies. 3th.ed. , Little, Brown, Boston, p.197-203, 1994.

14 - VINOGRADOV S \& YALOM ID. Groups de apoio para profissionais: considerações clínicas e objetivos. In:VINOGRADOV S \& YALOM ID, eds. Manual de psicoterapia de grupo.Artes Médicas, Porto Alegre, p.195200, 1992.

15- CONTEL JOB. Trabalhando com grupos em instituições: origens do método, teoria e prática. In: FRANKLIN JOJ, ed. Grupoterapia: Teoria e prática, Quick Press, Campinas, p. 207-228, 1997.

16 - SPONHOLZ JR A; PATON EJA; PESTANA DNR; STRACIERI ABPL; SIMÕES BP; ALBERTO FL; SARTI MH; CONTEL JO \& VOLTARELLI JC. Management of stress in the bone marrow transplant team by group reflection. In:Annual IBMTR/ ABMTR Participants Meeting, Vancouver, A3, p.3, 1997.

17 - CONTEL JOB; SPONHOLZ Jr A \& TÁPIA LER. Long term psychiatric liasion support group for high-stress facility: The Ribeirão Preto's bone marrow transplant team case (BMTT). J Bras Psiquiatr 48: 121-125, 1999.

17a - ANDRYKOWSKI MA; BRADY MJ \& HENSLEE-DOWNEY PJ. Psychosocial factors predictive of survival after allogeneic bone marrow transplantation for leukemia. Psychosom Med 1994; 56: 432-439.

17b - GREGUREK R; LABAR B; MRSIC M; BATINIC D; LADIKA I; BOGDANIC V; NEMET D; SKERLEV M; JAKIC-RAZUMOVIC J \& KLAIN E. Anxiety as a possible predictor of GVHD. Bone Marrow Transplant 18: 585-589, 1996.

17c - SULLIVAN AK; SZKRUMELAK N \& HOFFMAN LH. Psychological risk factors and early complications after bone marrow transplantation in adults. Bone Marrow Transplant 24: 1109-1120, 1999.
18 - CROWE K. Me and my marrow: A kid's guide to bone marrow transplants. IL: Fujisawa Healthcare, Deerfield1999.

18a - RODRIGUE JR; BOGGS SR; WEINER RS \& BEHEN JM. Mood, coping style and personality functioning among adult bone marrow transplant candidates. Psychosomatics 34: 159165,1993

18b- MOLASSIOTIS A. Further evaluation of a scale to screen for risk of emotional difficulties in bone marrow transplant recipients. J Adv Nursing 29: 922-927, 1999.

19 -BAKER F. Cancer facts and figures - 1997. American Cancer Society,Atlanta, 1997.

20 - FARRAN CJ.; HEARTH KA \& POPOVICH JM. Hope and hopelessness: Critical clinical constructs. Sage, New York, Thousand Oaks, CA, 1995.

21 - HERTY K. Fostering hope in terminally-ill people. J Adv Nurs 15: 1250-1259, 1990.

22 - TEMOSHOK L. The type $\mathrm{C}$ connection: The behavioral links to cancer and your health. Random House, New York, 1992.

23 - KOVÁCS MJ. Sofrimento psicológico de pacientes com câncer avançado em programas de cuidados paliativos. Bol Psicol 48: 25-47, 1994.

24 - KOPPMEINERS L; POST-WHITE J; GUTKNECHT S; CERONSKY C; NICKELSON K; DREW D; MACHEY KW \& KREITZER MJ. (1998) How healthcare professionals contribute to hope in patients with cancer. Oncol Nurs Forum 24: 1507-1513, 1997.

25 - TORRANO-MASETTI LM; SANTOS MA; OLIVEIRA EA \& SIMÕES BP. Counseling group for candidates waiting for hematopoietic cell transplantation: A psychological intervention. In: Abstract, Tandem Bone Marrow Transplantation Meetings American Society for Bone Marrow Transplantation, Los Angeles, p.19, 2000.

26 - TORRANO-MASETTI LM; SANTOS MA \& OLIVEIRA EA. Grupo preparatório para pacientes na fila de espera para transplante de medula óssea: avaliação de uma estratégia de intervenção. In: Resumos, XXIX Reunião Anual da Sociedade Brasileira de Psicologia (SBP), CampinasSP, p. 248, 1999

27 - STEWART S. Bone marrow transplants: A book of basics for patients. Blood \& Marrow Transplant Newsletter, Highland Park, Boston, 1995.

28 - LESKO LM. Bone marrow transplantation. In: HOLLAND J \& ROWLAND J, eds. Handbook of psychooncology: Psychological care for the patient with cancer. Oxford University Press, New York, p. 163-172, 1990.

29 - COOLEY ME. Quality of life in persons with non-small cell lung cancer: A concept analysis. Cancer Nurs 21: 151-161, 1998.

30 - PARKES CM. Luto: Estudos sobre a perda na vida adulta. Trad. Maria Helena Franco Bromberg. Summus, São Paulo, 1998

31 - ANDRYKOWSKI MA. Psychosocial factors in bone marrow transplantation: a review and recomendations for research. Bone Marrow Transplant 13:357-375, 1994.

32 - AARONSON NK. Quality of life: what is it? How should it be measured? Oncology 8:87-92, 1994. 
33 - WHEDON M. Quality of life in adult bone marrow transplant patients: beyond the first year. Semin Oncol Nurs 10: 42-57, 1994.

34 - WEINER EP. Quality of life after bone marrow transplantation. Oncology 8: 19-27, 1994.

35 - ALMEIDAAC; LOUREIRO SR \& VOLTARELLI JC. O ajustamento social e a qualidade de vida de pacientes submetidos ao transplante de medula óssea. Medicina- Ribeirão Preto 31: 296-304, 1998.

36 - HABERMAN M. Quality of life of adult long - term survivors of bone marrow transplantation: a quality analysis of narrative data. Oncol Nurs Forum 20: 1545-1553, 1993.

37 - BIAGGIO AMB; NATALÍCIO L \& SPIELBERGER CD. Desenvolvimento da forma experimental em português do Inventário de Ansiedade Traço-Estado - IDATE de Spielberger. Arq Bras Psicol 29:31-44, 1987.

38 - DELA COLETA MF. Escala Multidimensional de Locus de Controle de Levenson. Arq Bras Psicol 29: 79-97, 1987.

39 - BOTEGA NJ. Transtornos do humor em enfermaria de clínica médica e validação da escala de ansiedade e depressão. Rev Saúde Publica 29: 355-363, 1995.

40 - TRAUBENBERG NR. A prática do Rorshach. Cultrix, São Paulo, 1975.

41 - AUGRAS M. Teste de Rorschach.. Atlas e dicionário. 6 ed. Getúlio Vargas, Rio de Janeiro, 1986.

42 - VAN KOLCK OL. Testes Projetivos gráficos no diagnóstico psicológico. Temas Básicos Psicol 5: 13-54, 1984.
43 - HENGEVELD MW. Psychological aspects of bone marrow transplantation: a retrospective study of 17 long-term survivors. Bone Marrow Transplant 3: 69-75, 1988.

44 - BUSH NE. Quality of life of 125 adults surviving 6-18 years after bone marrow transplantation. Soc Sci Med 40: 479-490, 1995.

45 - ANDRYKOWSKI MA. 'Returning to normal' following bone marrow transplantation: outcomes, expectations and informed consent. Bone Marrow Transplant 15: 573-581, 1995.

46 - ALMEIDA AC. Avaliação psicológica e qualidade de vida de pacientes submetidos ao transplante de medula óssea. Dissertação de Mestrado, Faculdade de Filosofia Ciências e Letrad de Ribeirão Preto da USP, Ribeirão Preto, p. 1124, 1998.

47 - WELLISH D \& WOLCOTT DL. Psychological issues in bone marrow transplantation. In: FORMAN SJ; BLUME K \& THOMAS ED, eds. Bone marrow transplantation, Blackwell Scientific Publications, Boston, p. 556-571, 1994.

48 - MOFFATT A. A psicoterapia do oprimido: ideologia e técnica da psiquiatria popular. $6^{a}$ ed, Cortez, São Paulo, 1986.

49 - BAKER F. Psychosocial sequelae of bone marrow transplantation. Oncology 10: 87-1092, 1994.

Recebido para publicação em 13/06/2000

Aprovado para publicação em 11/07/2000 